
March 1936

\title{
ABSORPTION OF X-RAYS BY LEAD GLASSES AND LEAD BARIUM GLASSES
}

\author{
By George Singer
}

\section{ABSTRACT}

The results of a study of the protective properties of a group of typical flint and barium-flint glasses are reported. In chemical composition, the protective glasses analyzed were found to resemble closely the denser optical flint and barium-flint glasses. The protection coefficients of the glasses were determined by an ionization method; of the various component elements it was found that only lead and barium contribute appreciably to the protective effectiveness of the glasses.

For flint glass empirical relations were established between the protection coefficient and the chemical composition, density, and refractivity; for bariumflint glass an empirical relation is given between the protection coefficient and the lead-oxide and barium-oxide components of the glass.

\section{CONTENTS}

I. Introduction

II. Methods of determining the protection coefficient of a material _..- 234

III. Experimental procedure

IV. Description of glasses._.

V. Protection coefficient and quality of radiation

VI. Protection coefficient of glass for a narrow spectral band of radiation.

1. Flint glass

2. Barium-flint glass.

VII. Empirical relations for protection coefficient of flint glass

1. Protection coefficient and density 246

2. Protection coefficient and refractive index $\ldots \ldots \ldots 7$

3. Protection coefficient and chemical composition $\ldots \ldots$

VIII. Empirical relations for barium-flint glass

1. Effect of added barium oxide on protection coefficient.... 249

2. Protection coefficient and chemical composition $\ldots 250$

\section{INTRODUCTION}

Gorton, ${ }^{1}$ Dorsey, ${ }^{2}$ and Kaye and Owen ${ }^{3}$ have examined the X-ray protective properties of heavy flint glasses, and have correlated the protection coefficients ${ }^{4}$ of these glasses with the glass density. How-

1 W. S. Gorton, Am. J. Roentgenology 5, no. 10 (October 1918).

N. Ernest Dorsey, Am. J. Roentgenology (March 1919).

Kaye and Owen, Proc. Phys. Soc. London 35, 33D (1923).

- "Protection coefficient" has been defined by the American Advisory Committee on X-ray and Radium Protection as follows:

"The 'protection coefficient' of a protective material is the ratio of the thickness of lead to the thickness of material which absorbs a given X-ray beam to the same extent."

It is to be noted that the absorption coefficient of a material is a measure of its opacity to X-rays of a given quality as compared with that of metallic lead, and, therefore, depends not only upon the absorption properties of the material itself but upon those of lead as well. It is not a measure of the absolute opacity of the material. 
ever, in recent years X-ray flint glasses have been largely supplanted by X-ray barium-flint glasses which, from the point of view of protection, are essentially different. Our tests of X-ray glasses have shown that the findings of the earlier studies (references 1,2, and 3) are not directly applicable to the newer X-ray glasses without considerable extension and modification. This is principally because barium is of lower density and lower atomic number, and hence, has absorption properties differing from those of metallic lead. The object of the present study of X-ray glasses was:

1. To obtain the protection coefficient of flint and barium-flint glasses as a function of X-ray quality.

2 . To correlate the protection coefficient with such readily determined physical properties of glass as density and refractive index.

3. To determine the relation between the protection coefficient of the glass and its chemical composition.

\section{METHODS OF DETERMINING THE PROTECTION COEFFICIENT OF A MATERIAL}

The relative X-ray opacities of materials are usually determined by either a photographic or an ionization method. Inasmuch as these two methods do not always give results which are in good agreement, and this fact is not usually appreciated, a brief discussion of them will be given.

The photographic method consists in simultaneously radiographing a glass sample and a lead echelon consisting of a prepared series of lead filters. This is usually done by placing the sample and echelon side by side directly upon the cassette containing the photographic film, and exposing them to radiation. It is desirable to reduce the distance between the radiographed material and photographic film to a minimum so as to avoid overlapping of the shadows cast and the inclusion of uncertain amounts of scattered radiation from both test sample and lead echelon. Successive exposures on the same or different films are also undesirable, for obvious reasons. That lead filter which gives directly or by interpolation the same photographic density as the sample is taken to be the lead equivalent of the sample. From this the protection coefficient is calculated.

The ionization method consists in comparing the current in a suitable X-ray ionization chamber obtained by using the sample as filter with the currents similarly obtained using a series of graduated lead filters. That thickness of lead which would give the same ionization current as the glass sample is then taken to be the lead equivalent of the sample.

Of these two methods, the photographic is more commonly used, since it requires a less elaborate experimental setup. Its chief advantage is that, unlike the ionization method, a constant source of $\mathrm{X}$-rays is not essential, since the exposure of both the glass sample and the standard lead echelon are made simultaneously. With the ionization method the geometrical constants of the system used in making the measurements can be adjusted so as to minimize the effect of X-ray scattering from the glass and filters under test. By decreasing the solid angle subtended by the entrance diaphragm of the ionization chamber, and by sufficiently increasing the distance between the sample under test and the chamber, this scattering can be made 
negligible. These adjustments are not possible with the photographic method; and consequently the protection coefficient so obtained usually differs from that obtained by the ionization method.

The result from the photographic method differs from that of the ionization method in that the former registers not only the transmitted radiation but in addition the secondary radiation from the material. Although it is true that from the point of view of protection, there is no need to distinguish between transmitted and scattered radiation from a protective material, it is desirable to separate the two factors, absorption and scattering. Unless this is done, a reproducible measure of the lead equivalent or protection coefficient of a material is more or less doubtful. Moreover, since the secondary radiation from glass has a different spectral composition than that of metallic lead, it is questionable whether two such different radiations can be satisfactorily compared by photographic means. Little is

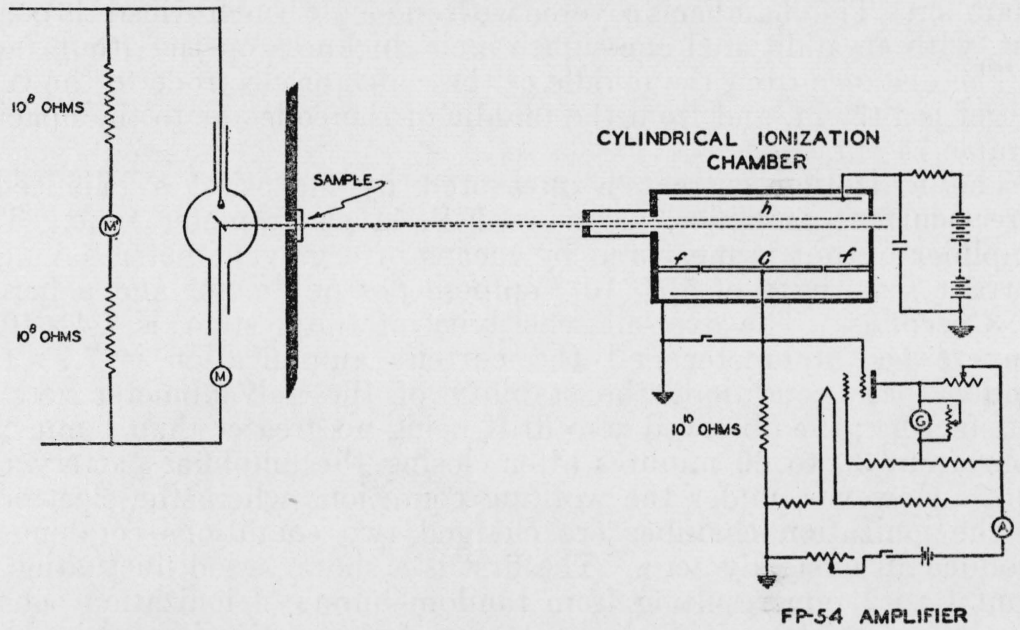

Figure 1.-Diagram of the apparatus used in determining the lead equivalent of a proteciive material.

known concerning the variation in photographic sensitivity with $\mathrm{X}$-ray quality, and in the absence of definite information on this point, it is unsafe to assume that the sensitivity of the emulsion used is not a function of wave length. ${ }^{5}$

\section{EXPERIMENTAL PROCEDURE}

The ionization method and experimental arrangement sketched in figure 1 were used here. For measuring the relative absorption properties of materials the cylindrical ionization chamber is better suited than is the parallel-plate ionization chamber commonly used in dosage standardization. The X-ray intensities which must be measured in opacity tests are necessarily very low; for most of those here reported the radiation intensity after filtration is about $10^{-4}$ times that of the incident radiation. It is desirable to have the volume of air ionized large enough to furnish ionization currents

5 R. B. Wilsey, Am. J. Roentgenology and Radium Therapy 32, 789 (1935). 
that are not troublesomely small. However, an increase in this volume augments at the same time the interelectrode capacity and the collector-to-ground capacity of the system, and the effect of both is to increase the period of the system and to produce an uncertain galvanometer zero because of induced currents resulting from random fluctuations in the potential difference between the high-potential electrode and ground.

The ionization chamber used is of the cylindrical open-air type. It consists of a thin aluminum cylinder electrode (h) spaced by hard-rubber posts from a concentric supporting brass tube $30 \mathrm{~cm}$ in diameter and $60 \mathrm{~cm}$ long, closed at the ends with aluminum. The edges of this electrode are somewhat rounded and separated several centimeters from the ends of the supporting cylinder so as to minimize field distortion. The collector electrode is a brass cylinder (c) about $1 \mathrm{~cm}$ in diameter and $30 \mathrm{~cm}$ long. Guard cylinders (f) of the same diameter extend to the earthed ends of the chamber. The chamber is covered with one-eighth inch oflead throughout, with an additional one-eighth inch thickness on the front face.

The distance from the middle of the collector electrode to the tube target is $147 \mathrm{~cm}$, and from the middle of the collector to the opacity sample $74 \mathrm{~cm}$.

The ionization current is measured by means of a balanced, ${ }^{6}$ direct-current amplifier, using an F.P.-54 electrometer tube. The amplifier output is measured by means of a galvanometer having a current sensitivity of $5.7 \times 10^{-9}$ ampere per millimeter and a period of 3 seconds. The over-all sensitivity of the system is $7.4 \times 10^{-15}$ ampere per millimeter and the current amplification is $7.7 \times 10^{5}$. Under these conditions the stability of the galvanometer zero is satisfactory; the observed zero drift being no greater than $1 \mathrm{~mm}$ per hour from 30 to 60 minutes after closing the amplifier battery circuit. However, under the working conditions where the electrodes of the ionization chamber are charged two conditions combine to produce an unsteady zero. The first is a short period fluctuation of from 1 to $2 \mathrm{~mm}$ resulting from random bursts of ionization caused by alpha particles originating in traces of radioactive impurities ${ }^{78}$ in the electrodes, and from radioactive contamination of the free air within the chamber. Because of their short period these fluctuations are readily distinguished from those resulting from variations in the X-ray input to the ionization chamber; and therefore they do not seriously affect the accuracy with which a given deflection can be read. A more serious cause of uncertainty in the galvanometer zero is the irregular displacement current produced in the ionization chamber by random fluctuations in the potential difference between the electrodes arising from variations in the emf. of the high-voltage supply. The interelectrode capacity of the chamber used is only $53 \mu \mu \mathrm{f}$, but a sudden variation of 0.1 volt in the potential difference produces a displacement current which registers a deflection of $30 \mathrm{~mm}$ at full sensitivity. Since 1,000 volts are required for saturation, it is evident that an extremely constant high-voltage supply is essential. Large B batteries in good condition are satisfactory.

- Lee A. DuBridgejand Hart Brown, Rev. Sci. Inst. 4, 532 (1933).

7 J. A. Bearden, Rev. Sci. Inst. 4, 271 (1933).

8 Ziegert, Z. Phys. 46, 668 (1927). 
The ionization current was measured by direct deflection. Inasmuch as ionization readings for both metallic lead and for glass are here directly compared any variation from linear amplification ${ }^{9}$ in this system does not affect the results.

$\mathrm{X}$-rays were generated by means of a thick-wall therapy X-ray tube supplied with power by a $200-\mathrm{kv}$ constant-potential generator previously described. ${ }^{10}$ The power-supply input is stabilized; variations in power input being not greater than \pm 0.3 percent. The cathode of the $\mathrm{X}$-ray tube was heated by storage batteries. Both tube voltage and current were continuously observed and controlled by the operator from his station near the amplifier. It is estimated that variations in $\mathrm{X}$-ray input to the ionization chamber did not exceed \pm 0.5 percent. When the $\mathrm{X}$-ray generator is manually controlled these variations are reduced to approximately \pm 0.25 percent. The potential difference across the X-ray tube was read directly by means of an accurately calibrated, high-resistance voltmeter ${ }^{11}$ consisting of a microammeter in series with two resistance units of 100 megohms each.

\section{DESCRIPTION OF GLASSES}

Commercial X-ray protective glasses now available are of two kinds:

1. Dense flint glasses whose X-ray protective qualities are practically determined by their lead content alone.

2. Barium-flint glasses whose effectiveness arises from the presence of both lead and barium.

Other constituents of both types of X-ray glasses are of comparatively low atomic number and hence do not contribute much to the protective qualities of these materials. The recent trend in X-ray glasses has been toward those of higher protection coefficient, that is, from the flint to the barium-flint glasses. Although the former are now relatively unimportant commercially as a protective product, they are here of interest as a means of understanding the newer barium-flint X-ray glasses.

This report is based on a study of 30 glasses obtained from a number of different sources. Of these, 22 are commercial X-ray glasses selected from a group of 53 as being representative of protective $\mathrm{X}$-ray glasses commercially available at the present time. For the purpose of comparison, 8 standard optical glasses were included; 6 of these were obtained from the Glass Section of this Bureau.

Although lead and barium are the effective components of protective glasses, in considering the protective properties of these glasses it is convenient to consider the protection coefficient as a function of the oxides of these metals rather than of the metals themselves.

In tables 1 and 2 there are listed all flint and barium-flint X-ray glasses studied, together with such of their chemical and physical properties as are of interest in connection with this study.2

\footnotetext{
- The ratio between output current and input current for the system used varies from a straight line by approximately one percent for deflections up to the maximum obtained. Where strictly linear amplification is essential, it is necessary to operate the electrometer tube on a fixed point of its plate current-grid potential characteristic. This is best done by the introduction of a potentiometer in the grid circuit, and the use of the system as a null instrument.

10 L. S. Taylor, BS J. Research 2, 771 (1929) RP56.

11 L. S. Taylor, BS J. Research 5, 609 (1930) RP217.

12 We are indebted to J. I. Hoffman for checking the chemical analyses of the glasses listed; to L. W. Tilton for all refractivity measurements; and to E. L. Peffer for all density determinations.
} 
classification of each glass is given in column 2. BC-1, BC-2, and $\mathrm{BC}-3$ of table 2 are optical barium crown glasses, not used for X-ray protection, but included here for purposes of comparison. The chemical analyses given for $\mathrm{PbO}$ and $\mathrm{BaO}$ content were obtained mostly from the glass manufacturers. In several cases our measurements of the opacity to X-rays indicated that the manufacturer's analysis must be in error. In each of these a chemical analysis made by Mr. Hoffman at this Bureau confirmed our views; and for these Mr. Hoffman's analyses are recorded instead of those given by the manufacturer.

TABLE 1.-List of fint glasses

\begin{tabular}{|c|c|c|c|c|c|c|c|c|c|c|c|c|c|}
\hline \multirow{2}{*}{ Glass } & \multirow{2}{*}{ Classification } & \multirow{2}{*}{$\begin{array}{l}\text { Num- } \\
\text { ber of } \\
\text { sam- } \\
\text { ples } \\
\text { of } \\
\text { each } \\
\text { glass }\end{array}$} & \multirow{2}{*}{$\begin{array}{c}\text { Re- } \\
\text { frac- } \\
\text { tive } \\
\text { index } \\
n_{\mathrm{D}}\end{array}$} & \multirow{2}{*}{$\begin{array}{l}\text { Den- } \\
\text { sity }\end{array}$} & \multirow{2}{*}{$\mathrm{PbO}$} & \multirow{2}{*}{$\mathrm{BaO}$} & \multicolumn{7}{|c|}{ Protection coefficient (percent) for- } \\
\hline & & & & & & & $\begin{array}{l}90 \\
\mathrm{kV}\end{array}$ & $\begin{array}{l}105 \\
\mathrm{kV}\end{array}$ & $\begin{array}{l}120 \\
\mathrm{kV}\end{array}$ & $\begin{array}{l}135 \\
\mathrm{kv}\end{array}$ & $\begin{array}{l}150 \\
\mathrm{kV}\end{array}$ & $\begin{array}{l}165 \\
\mathrm{kV}\end{array}$ & $\begin{array}{l}195 \\
\mathrm{kV}\end{array}$ \\
\hline $\mathrm{F}-1$ & Com & \multirow{6}{*}{$\begin{array}{l}2 \\
1 \\
1 \\
2 \\
1 \\
1\end{array}$} & \multirow{6}{*}{$\begin{array}{l}1.618 \\
1.622 \\
1.647 \\
1.700 \\
1.721 \\
1.775\end{array}$} & \multirow{6}{*}{$\begin{array}{l}3.609 \\
3.630 \\
3.859 \\
4.310 \\
4.479 \\
4.932\end{array}$} & \multirow{6}{*}{$\begin{array}{c}\% \\
46.1 \\
46.0 \\
51.5 \\
60.3 \\
65.0 \\
69.8\end{array}$} & \multirow{6}{*}{$\begin{array}{l}\% \\
0.0 \\
0.0 \\
0.0 \\
0.0 \\
0.0 \\
0.0\end{array}$} & \multirow{6}{*}{$\begin{array}{l}14.96 \\
15.13 \\
17.84 \\
22.30 \\
23.92 \\
28.42\end{array}$} & \multirow{6}{*}{$\begin{array}{l}14.93 \\
14.96 \\
17.43 \\
22.43 \\
24.20 \\
28.66\end{array}$} & \multirow{6}{*}{$\begin{array}{l}15.06 \\
15.17 \\
17.53 \\
22.51 \\
23.99 \\
28.77\end{array}$} & \multirow{6}{*}{$\begin{array}{l}14.94 \\
14.90 \\
17.49 \\
22.43 \\
24.13 \\
28.66\end{array}$} & \multirow{6}{*}{$\begin{array}{l}15.11 \\
15.03 \\
17.55 \\
22.32 \\
23.99 \\
28.62\end{array}$} & \multirow{4}{*}{$\begin{array}{l}14.84 \\
14.88 \\
17.35 \\
22.60\end{array}$} & \multirow{5}{*}{$\begin{array}{l}14.72 \\
14.94 \\
17.25 \\
22.51\end{array}$} \\
\hline $\mathrm{F}-3$ & Optic & & & & & & & & & & & & \\
\hline$F-4$ & & & & & & & & & & & & & \\
\hline $\mathrm{F}-\mathrm{s}$ & Commercial X-rays & & & & & & & & & & & & \\
\hline F-9c & & & & & & & & & & & & & \\
\hline $\mathrm{F}-12$ b & Optical flint_........ & & & & & & & & & & & 28.52 & 28.50 \\
\hline
\end{tabular}

a Chemical analysis made by Mr. Hoffman of NBS Chemistry Division.

b Batch analyses submitted by Mr. Finn of NBS Glass Section.

- Chemical analyses submitted by manufacturer.

TABLE 2.-List of barium-fint and barium-crown glasses

\begin{tabular}{|c|c|c|c|c|c|c|c|c|c|c|c|c|c|}
\hline \multirow[b]{2}{*}{ Glass } & \multirow[b]{2}{*}{ Classification } & \multirow{2}{*}{$\begin{array}{l}\text { Num- } \\
\text { ber of } \\
\text { sam- } \\
\text { ples of } \\
\text { each } \\
\text { glass }\end{array}$} & \multirow{2}{*}{$\begin{array}{l}\text { Re- } \\
\text { frac- } \\
\text { tive } \\
\text { index } \\
n_{\mathrm{D}}\end{array}$} & \multirow[b]{2}{*}{$\begin{array}{l}\text { Den- } \\
\text { sity }\end{array}$} & \multirow[b]{2}{*}{$\mathrm{PbO}$} & \multirow[b]{2}{*}{$\mathrm{BaO}$} & \multicolumn{7}{|c|}{ Protection coefficient (percent) for- } \\
\hline & & & & & & & $\begin{array}{c}90 \\
\mathrm{kV}\end{array}$ & $\begin{array}{l}105 \\
\mathrm{kv}\end{array}$ & $\begin{array}{l}120 \\
\mathrm{kV}\end{array}$ & $\begin{array}{r}135 \\
\mathrm{kV}\end{array}$ & $\begin{array}{c}150 \\
\text { kV }\end{array}$ & $\begin{array}{l}165 \\
\mathrm{kv}\end{array}$ & $\begin{array}{l}195 \\
\mathrm{kv}\end{array}$ \\
\hline $\begin{array}{l}\text { BF-1 a } \\
\text { BF-2 } \\
\text { BF-3 }- \\
\text { BF-5 } \\
\text { BF-7 }\end{array}$ & $\begin{array}{l}\text { Optical barium flint. } \\
\text { Commercial X-ray. }\end{array}$ & $\begin{array}{l}1 \\
1 \\
2 \\
2 \\
2\end{array}$ & \begin{tabular}{|l|}
1.603 \\
1.614 \\
1.6949 \\
1.6992
\end{tabular} & $\begin{array}{l}3.392 \\
3.479 \\
3.572 \\
4.323 \\
4.361\end{array}$ & $\begin{array}{l}\% \\
6.87 \\
23.5 \\
44.1 \\
47.1 \\
45.38\end{array}$ & $\mid \begin{array}{c}\% \\
29.15 \\
14.5 \\
<.1 \\
14.35 \\
15.02\end{array}$ & $\begin{array}{l}15.35 \\
14.80 \\
26.43 \\
26.60\end{array}$ & \begin{tabular}{|l|}
14.86 \\
14.78 \\
26.56 \\
26.90
\end{tabular} & $\begin{array}{l}14.62 \\
14.81 \\
26.31 \\
26.46\end{array}$ & $\begin{array}{l}13.79 \\
14.66 \\
25.76 \\
25.96\end{array}$ & $\begin{array}{l}13.56 \\
14.74 \\
24.65 \\
24.93\end{array} \mid$ & $\begin{array}{r}9.89 \\
12.75 \\
14.81 \\
\hdashline 23.57\end{array}$ & $\begin{array}{r}8.89 \\
11.93 \\
14.72 \\
21.56 \\
22.26\end{array}$ \\
\hline 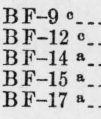 & 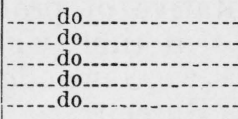 & $\begin{array}{l}3 \\
2 \\
1 \\
2 \\
1\end{array}$ & \begin{tabular}{|l|}
1.7146 \\
1.723 \\
\hdashline 1.7254 \\
-0
\end{tabular} & $\begin{array}{l}4.423 \\
4.587 \\
4.604 \\
4.609 \\
4.609\end{array}$ & $\begin{array}{l}60.0 \\
52.0 \\
53.15 \\
52.6 \\
51.2\end{array}$ & $\begin{array}{l}<.1 \\
13.94 \\
13.01 \\
14.7 \\
15.5\end{array}$ & $\left|\begin{array}{l}23.49 \\
29.42 \\
29.98 \\
29.88 \\
-\cdots\end{array}\right|$ & $\begin{array}{l}23.63 \\
29.38 \\
29.74 \\
30.15 \\
29.7\end{array}$ & $\begin{array}{l}23.58 \\
29.14 \\
29.22 \\
29.83 \\
-\cdots\end{array}$ & $\begin{array}{l}23.64 \\
28.61 \\
28.80 \\
29.27 \\
-\cdots\end{array}$ & $\left|\begin{array}{l}23.48 \\
27.70 \\
27.73 \\
28.20 \\
28.0\end{array}\right|$ & $\mid \begin{array}{l}-\cdots .17 \\
26.05 \\
\cdots \cdots\end{array}$ & \begin{tabular}{l}
23.43 \\
24.90 \\
25.02 \\
\hdashline
\end{tabular} \\
\hline $\begin{array}{l}\text { BF-18 } \\
\text { B F-20 } \\
\text { BF-22 } \\
\text { B }-24 \text { a } \\
\text { B F-27 a d }\end{array}$ & 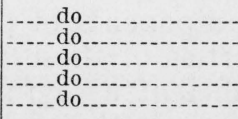 & $\begin{array}{l}2 \\
1 \\
2 \\
2 \\
1\end{array}$ & $\begin{array}{l}1.741 \\
1.742 \\
1.7396 \\
1.7428 \\
--.-\end{array}$ & $\begin{array}{l}4.690 \\
4.698 \\
4.712 \\
4.734 \\
4.837\end{array}$ & $\begin{array}{l}62.2 \\
61.6 \\
60.9 \\
62.1 \\
52.6\end{array}$ & $\begin{array}{r}2.34 \\
2.52 \\
6.5 \\
5.3 \\
14.6\end{array}$ & $\mid \begin{array}{l}26.88 \\
27.01 \\
28.43 \\
28.27 \\
31.02\end{array}$ & $\mid$\begin{tabular}{l|}
26.88 \\
27.11 \\
28.62 \\
28.69 \\
31.30
\end{tabular} & $\left|\begin{array}{l}26.94 \\
27.17 \\
28.64 \\
28.49 \\
31.09\end{array}\right|$ & $\begin{array}{l}26.90 \\
27.24 \\
28.54 \\
28.42 \\
30.22\end{array}$ & $\begin{array}{l}26.57 \\
26.99 \\
27.91 \\
27.85 \\
28.80\end{array}$ & $\begin{array}{l}26.63 \\
27.54 \\
27.63 \\
28.09\end{array}$ & $\begin{array}{l}26.41 \\
26.81 \\
27.08 \\
26.23\end{array}$ \\
\hline $\begin{array}{l}\text { BF-28 a e } \\
\text { BF-29 a } \\
\text { BF-30 a } \\
\text { BF-31 a }\end{array}$ & $-1 \mathrm{do}$ & $\begin{array}{l}1 \\
1 \\
1\end{array}$ & & $\begin{array}{l}4.856 \\
4.906 \\
5.055 \\
----\end{array}$ & $\begin{array}{l}62.0 \\
62.0 \\
62.0 \\
61.0\end{array}$ & $\begin{array}{r}5.3 \\
8.0 \\
10.0 \\
9.7\end{array}$ & $\begin{array}{l}30.50 \\
31.37 \\
33.38 \\
----\end{array}$ & $\begin{array}{l}30.29 \\
31.30 \\
33.39 \\
32.0\end{array}$ & $\begin{array}{l}30.27 \\
31.30 \\
32.97 \\
--\cdot-\end{array}$ & $\begin{array}{l}30.19 \\
31.01 \\
31.67 \\
30.6\end{array}$ & $\begin{array}{l}29.60 \\
30.14 \\
31.69 \\
-\ldots\end{array}$ & $\begin{array}{l}29.29 \\
29.83 \\
31.16 \\
-\ldots\end{array}$ & $\begin{array}{l}28.25 \\
28.44 \\
29.25 \\
28.4\end{array}$ \\
\hline $\begin{array}{l}\text { BC-1 } \\
\text { BC-2 } \\
\text { BC-3 }-3\end{array}$ & $\begin{array}{l}\text { Optical barium crown } \\
\text { do }\end{array}$ & \begin{tabular}{l|l}
1 \\
1 \\
1
\end{tabular} & \begin{tabular}{c}
1.572 \\
\hdashline 1.606
\end{tabular} & $\left|\begin{array}{l}3.205 \\
3.513 \\
3.701\end{array}\right|$ & $\begin{array}{l}0.0 \\
0.0 \\
0.0\end{array}$ & $\begin{array}{l}31.7 \\
38.40 \\
42.7\end{array}$ & $\mid$\begin{tabular}{l}
14.03 \\
\hdashline 23.94 \\
-1
\end{tabular} & \begin{tabular}{|l|}
12.41 \\
20.60
\end{tabular} & \begin{tabular}{l}
11.28 \\
\hdashline 17.31
\end{tabular} & $\begin{array}{l}10.23 \\
14.95\end{array}$ & $\begin{array}{r}9.45 \\
\hdashline 13.52\end{array}$ & $\begin{array}{r}8.45 \\
10.04 \\
12.05\end{array}$ & $\begin{array}{r}7.62 \\
8.71 \\
10.56\end{array}$ \\
\hline
\end{tabular}

a Chemical analyses submitted by manufacturer.

b Batch analyses submitted by Mr. Finn of NBS Glass Section.

- Chemical analyses made by Mr. Hoffman of NBS Chemistry Division.

d Glass BF-27 contains $5 \%$ of $\mathrm{TiO}_{2}$.

- Glass BF-28 contains $2 \%$ of $\mathrm{UO}_{3}$. 
It should be noted that the commercial X-ray glasses of both the flint and barium-flint types are very similar in their chemical and physical properties to the typical optical glasses of these types. The $\mathrm{X}$-ray glasses are different only in that their content of lead and barium oxide is, in general, greater.

\section{PROTECTION COEFFICIENT AND QUALITY OF RADIATION}

The manner in which the protection coefficient of a glass depends upon the quality of the incident X-radiation is of particular interest. If there is a marked variation in the protection coefficient of a glass as the X-ray quality is varied, the coefficient determined for any one quality may be quite adequate for calculating the glass thickness required to meet X-ray safety recommendations ${ }^{13}$ for that particular

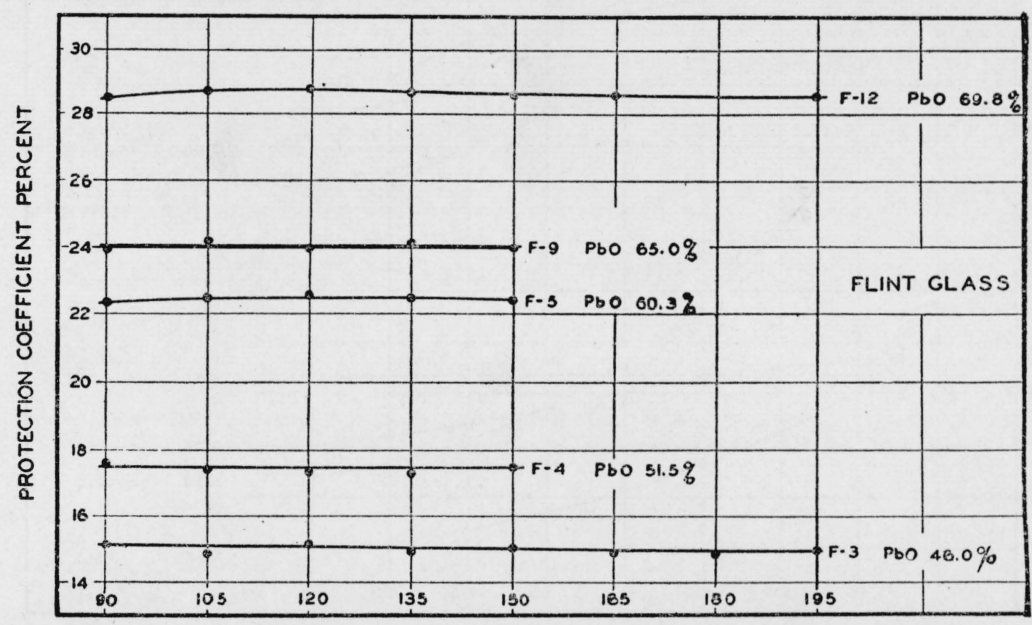

TUBE POTENTIAL KILOVOLTS

FIgURE 2.-The variation of the protection coefficient of fint glass with X-ray tube potential.

radiation but may be dangerously inadequate for a corresponding calculation for radiation of another quality. In such a case it is obviously meaningless to speak, as is often done, of the protection coefficient or lead equivalent of the glass unless the quality of radiation for which the coefficient applies is also specified.

The protection coefficient of a flint glass, which depends for its protective quality almost wholly on its lead content, is, in general, independent of the radiation quality. This is apparent from figure 2 in which the protection coefficient of the glasses listed in table 1 is plotted as a function of the excitation potential on the X-ray tube. Here the locus of the protection coefficient of any one flint glass is nearly a horizontal straight line. For most glasses of this type there appears to be a very slight, though negligible, maximum at about $105 \mathrm{kv}$, which is probably due to the light oxide components of the glass.

13 Handb. BS HB15 (1931). 
As shown in figure 3 , the protection coefficient of a barium-flint glass, in contrast with that of a flint glass, is not independent of radiation quality. The protection coefficient here yields a curve with a maximum at about $105 \mathrm{kv}$ irrespective of the amount of barium present. The accentuation of the maximum increases, however, with the increase of barium content, glasses containing relatively large quantities of $\mathrm{BaO}$ having the most marked maxima. For bariumcrown glasses, such as $\mathrm{BC}-1$ and $\mathrm{BC}-3$, the variation of protective coefficient with radiation quality is most marked. The maxima for

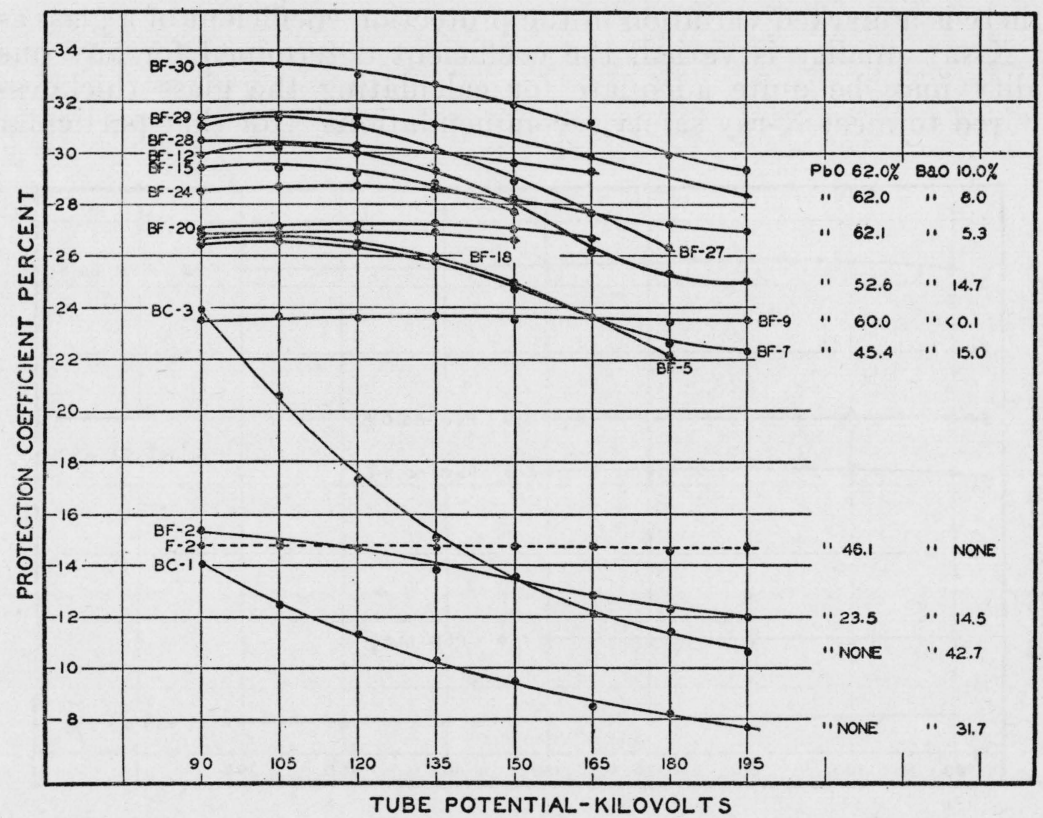

FIGURE 3.-The variation of the protection coeffcient of barium-flint and bariumcrown glass with X-ray tube potential.

these glasses are not shown since they lie below the tube-voltage ranges used.

A comparison between the protection coefficient of a flint and a barium-flint glass containing the same percentage of $\mathrm{PbO}$ is of interest in that effectiveness of the $\mathrm{BaO}$ component of the barium-flint glass then becomes apparent. In order to facilitate such a comparison, the protection coefficient curve of a flint glass, $\mathrm{F}-2$, having about the same $\mathrm{PbO}$ content as barium-flint $\mathrm{BF}-7$, has been included in figure 3 . Although this is a typical case, other examples are available between glasses listed in tables 1 and 2. Comparing curves, F-2 and BF-7 reveals that the protection coefficient of a barium-flint glass is considerably greater than that of a flint glass containing the same percentage of $\mathrm{PbO}$. This difference is especially marked in the vicinity of the maximum for 105-kv X-rays, but with increasing hardness of the radiation the difference in coefficients diminishes. 
It is obvious that the protection coefficient of a barium-flint glass cannot be less than that of a flint glass containing the same percentage of $\mathrm{PbO}$. This point is of practical interest, since it defines the lower limit of the protection coefficient of a barium-flint glass in terms of the protection coefficient of a flint glass containing the same $\mathrm{PbO}$ component. The protection coefficient of the latter glass does not vary appreciably with voltage and is readily determined from any one of several physical and chemical properties of the glass.

\section{PROTECTION COEFFICIENT OF GLASS FOR A NARROW SPECTRAL BAND OF RADIATION}

\section{FLINT GLASS}

In order to understand the characteristic differences between X-ray glasses of the flint and barium-flint types described in the preceding section, it is convenient to set up equations for the protection coefficient of a glass as a function of the absorption coefficients of its component elements. To do so, it is necessary to make assumptions concerning experimental conditions which in practice cannot be rigorously fulfilled. These assumptions are:

1. That the radiation for which the coefficient is defined is homogeneous in frequency.

2. That the filters used are so thin and the X-ray beam so collimated that all incident rays traverse equal thicknesses of filter.

3. That the filter thickness is so small that the effective wave length of the radiation is not appreciably altered by filtration when the radiation used is not strictly homogeneous with respect to frequency.

The first of these conditions is never fulfilled; X-ray glasses are intended primarily for protection against heterogeneous radiation, and tests are made using such radiation. However, as is already evident from figure 2 and the discussion of the preceding section, the wave-length effect is very small for flint glasses and it may, therefore, be expected, as is indeed the case, that for such glasses the protection coefficient calculated for a narrow spectral band of radiation is a satisfactory approximation of the experimentally determined value for heterogeneous radiation. For barium-flint glasses the case is, however, quite different since there is considerable variation in protection coefficient with variation in radiation quality. Consequently the protection coefficient for barium-flint glasses calculated for a narrow spectral band is difficult to interpret and is not directly comparable with the experimental value. However, even for bariumflint glasses the equations derived for a narrow spectral band of $\mathrm{X}$-rays are valuable in that they reveal the relation whereby the protection coefficient changes with variation in radiation quality.

The second assumed condition can be approximated in practice, as has here been done, by diaphragming the beam so that for all rays there is little difference in path-length through the filter.

The glass filters used were approximately one-fourth inch thick. Since filters of such thickness harden the incident heterogeneous radiation considerably, the further assumption is involved that the quality changes resulting from filtration through the corresponding thickness of metallic lead and through glass are identical. 
Let a beam of a narrow spectral band of radiation of intensity $I_{0}$, be reduced to intensity $I$, on traversing a glass sample of thickness $X_{\mathrm{gl}}$. Now let a filter of metallic lead be selected of such thickness, $X_{\mathrm{Pb}}$, that it, also, will reduce the intensity of the X-ray beam from $I_{0}$ to $I$. Then

$$
I=I_{0} e^{-\mu_{\mathrm{g} 1} X_{\mathrm{g} 1}}=I_{0} e^{-\mu \mathrm{P}_{\mathrm{b}} X_{\mathrm{Pb}}},
$$

where $\mu_{\mathrm{g} 1}$ and $\mu_{\mathrm{Pb}}$ are respectively the linear-absorption coefficients of the glass sample and the metallic-lead filter for the X-radiation in question. From equation 1 and the definition of the protection coefficient $(C)^{14}$, it follows that:

$$
C=\frac{X_{\mathrm{Pb}}}{X_{\mathrm{g} 1}}=\frac{\mu_{\mathrm{g} 1}}{\mu_{\mathrm{Pb}}}=\frac{\mu_{\mathrm{g} 1}}{(\mu / \rho)_{\mathrm{Pb}} \cdot \rho_{\mathrm{Pb}}},
$$

where $(\mu / \rho)_{\mathrm{Pb}}$ is the mass absorption coefficient for lead for the $\mathrm{X}$-radiation in question, and $\rho_{\mathrm{Pb}}=11.34$ is the density of lead. Since the mass absorption coefficient of an element is essentially independent of its physical or chemical state ${ }^{15}$ it is possible to express the linear absorption coefficients of the glass sample, $\mu_{\mathrm{gl}}$, in terms of the mass absorption coefficients of its several component elements, $(\mu / \rho)_{1},(\mu / \rho)_{2}$, etc., as follows:

$$
\mu_{\mathrm{g} 1}=\rho_{\mathrm{g} 1}\left[P_{1}(\mu / \rho)_{1}+P_{2}(\mu / \rho)_{2} \cdots P_{n}(\mu / \rho)_{n}\right],
$$

where $P_{1}, P_{2}, P_{3}$, etc. are the ratios of the mass of each component to the total mass of the glass; $(\mu / \rho)_{1},(\mu / \rho)_{2}$, etc. are the mass absorption coefficients of these components; and $\rho_{\mathrm{g} 1}$ is the glass density. Equation 2 then becomes:

$$
C=\frac{\rho_{\mathrm{g} 1}}{\rho_{\mathrm{Pb}}}\left[P_{1} \frac{(\mu / \rho)_{1}}{(\mu / \rho)_{\mathrm{Pb}}}+P_{2} \frac{(\mu / \rho)_{2}}{(\mu / \rho)_{\mathrm{Pb}}} \cdots \cdots P_{n} \frac{(\mu / \rho)_{n}}{(\mu / \rho)_{\mathrm{Pb}}}\right]
$$

Since lead is the most important component in all protective $\mathrm{X}$-ray glasses, it is convenient to rewrite equation 4 as follows:

$$
C=\frac{\rho_{\mathrm{g} 1}}{\rho_{\mathrm{Pb}}} \cdot P_{\mathrm{Pb}}+\frac{\rho_{\mathrm{g} 1}}{\rho_{\mathrm{Pb}}}\left[P_{2} \frac{(\mu / \rho)_{2}}{(\mu / \rho)_{\mathrm{Pb}}}+P_{3} \frac{(\mu / \rho)_{3}}{(\mu / \rho)_{\mathrm{Pb}}} \cdots P_{n} \frac{(\mu / \rho)_{n}}{(\mu / \rho)_{\mathrm{Pb}}}\right] .
$$

By means of equation 5 it is possible to calculate the protection coefficient $C$ of any glass for a narrow spectral beam of radiation, having given the composition and density of the glass and the mass absorption coefficient of each component element for that radiation. The total protection coefficient $C$ is expressed as the sum of two quantities: The first of these gives the component of the total coefficient due to the metallic lead contained in the glass; the second is the component of the total coefficient due to the presence of all component elements other than lead. The first right-hand term involves no quantity which varies with the quality of the incident radiation; the second involves the mass absorption coefficient of metallic lead and of each element contained in the glass, all of which are functions of radiation quality. It is therefore to be expected that the protection coefficient of any glass is independent of radiation

14 See footnote 4

is See, for example, Int.s. 
quality only to the extent that the component of the total-protection coefficient due to elements other than lead is negligibly small as compared with that due to the lead content of the glass.

That the component of the total-protection coefficient due to elements other than lead is small for flint glass is evident from table 3. Here the protection coefficients of four flint glasses as calculated by means of equation 5 for wave lengths .098 and $.710 \mathrm{~A}$ are compared with the experimentally determined values for 90 and $150 \mathrm{kv}$. The calculated coefficients given in columns 3 and 4 are lower than the experimentally determined values of columns 5 and 6 . The agree-

TABLE 3.-Protection coefficients of four typical flint glasses as calculated by equation 5 compared with experimentally determined values

\begin{tabular}{|c|c|c|c|c|c|c|c|}
\hline 1 & 2 & 3 & 4 & 5 & 6 & 7 & 8 \\
\hline \multirow{3}{*}{ Glass } & \multirow{3}{*}{$\mathrm{PbO}$} & \multicolumn{4}{|c|}{ Protection coefficient (percent) } & \multirow{2}{*}{\multicolumn{2}{|c|}{$\begin{array}{l}\text { Fraction of total cal- } \\
\text { culated coefficient } \\
\text { due to components } \\
\text { of glass other than } \\
\text { lead for: }\end{array}$}} \\
\hline & & \multicolumn{2}{|c|}{ Calculated for a: } & \multicolumn{2}{|c|}{ Observed for: } & & \\
\hline & & $\lambda=.098 \mathrm{~A}$ & $\lambda=.710 \mathrm{~A}$ & $150 \mathrm{kV}$ & $90 \mathrm{kv}$ & $\lambda=.098 \mathrm{~A}$ & $\lambda=.710 \mathrm{~A}$ \\
\hline $\begin{array}{l}\mathrm{F}-3 \\
\mathrm{~F}-4 \\
\mathrm{~F}-5\end{array}$ & \begin{tabular}{|c|} 
Percent \\
46.0 \\
51.5 \\
60.3 \\
69.8
\end{tabular} & $\begin{array}{l}14.5 \\
17.1 \\
22.1 \\
28.6\end{array}$ & $\begin{array}{l}14.3 \\
16.9 \\
21.8 \\
28.6\end{array}$ & $\begin{array}{l}15.0 \\
17.6 \\
22.3 \\
28.6\end{array}$ & $\begin{array}{l}15.1 \\
17.8 \\
22.3 \\
28.4\end{array}$ & $\begin{array}{r}0.055 \\
.046 \\
.035 \\
.012\end{array}$ & $\begin{array}{r}0.044 \\
.036 \\
.026 \\
.014\end{array}$ \\
\hline
\end{tabular}

a The mass absorption coefficients used in these calculations were taken from data tabulated by Compton and Allison, X-rays in Theory and Practise, p. 800 (D. Van Nostrand Co. Inc., New York, 1935).

ment, however, becomes satisfactory for the denser flint glasses. It should be noted that glasses F-3 and F-4 are optical flint glasses, which are lighter than most $\mathrm{X}$-ray glasses of this type. They are included here because it was desired to test the validity of equation 5 for glasses lying immediately outside the range of typical X-ray glasses. Glass $\mathrm{F}-5$ is a typical X-ray flint. Glass F-12 is a very dense optical flint, heavier than any X-ray flint tested. In columns 6 and 7 of table 3 there is given for each glass the fraction of the calculated protection coefficient due to glass components other than metallic lead. For the dense flint glasses the total contribution of all elements other than lead is small, being of the order of 2 or 3 percent.

If it is therefore assumed that for heavy flint glass the effect on the coefficient of all elements other than lead is negligible, equation 5 can be simplified by dropping the second term, which gives:

$$
C=\frac{\rho_{\mathrm{g} 1}}{\rho_{\mathrm{Pb}}} P_{\mathrm{Pb}}
$$

Equation 6 then gives an approximation for the protection coefficient of a heavy flint glass simply in terms of the percentage of lead it contains, the glass density, and the density of lead. Since the density of lead is 11.34 and that of heavy flint glass about 4 , it follows that for such glasses the protection coefficient is roughly equal numerically to one-third the percentage of lead contained. The statement is occasionally made that a flint glass containing - say 60 $49283-36-3$ 
percent of lead-will have a protection coefficient of 60 percent; but this is not to be expected from equation 6 ; and that it is not true is evident from any one of the curves given in figure 2. By means of equation 5 the chief characteristics of flint glass as a protective material (as found experimentally) can be explained, namely:

1. The protection coefficient of a flint glass is practically independent of radiation quality.

2. All elements contained in a flint glass other than lead contribute little to the value of the glass as a protective material.

\section{BARIUM-FLINT GLASS}

It has already been noted in connection with the discussion of figure 3 that a barium-flint glass has an appreciably greater protection coefficient than a flint glass containing the same percentage of lead oxide. This is to be expected since the atomic number of barium (56) is considerably greater than that of most elements found in glass; however, the marked protective effectiveness of barium for heterogeneous radiation of about $105 \mathrm{kv}$ cannot be attributed to this cause alone. It is convenient to rewrite equation 5 for a barium-flint glass as follows:

$$
C=\frac{\rho_{\mathrm{g} 1}}{\rho_{\mathrm{Pb}}} \cdot P_{\mathrm{Pb}}+\frac{\rho_{\mathrm{g}} 1}{\rho_{\mathrm{Pb}}}\left(P_{\mathrm{Ba}} \cdot \frac{(\mu / \rho)_{\mathrm{Ba}}}{(\mu / \rho)_{\mathrm{Pb}}}\right)+\frac{\rho_{\mathrm{g} 1}}{\rho_{\mathrm{Pb}}} \sum \frac{(\mu / \rho)_{\tau}}{(\mu / \rho)_{\mathrm{Pb}}},
$$

where $P_{\mathrm{Ba}}$ is the fraction of the total mass of the glass which is bariumhaving a mass absorption coefficient $(\mu / \rho)_{\mathrm{Ba}}$. Since the percentage of the light elements (those other than barium and lead) in an X-ray barium-flint glass is less than that in a flint glass containing the same percentage of lead, it is to be expected that the contribution toward the protection coefficient made by the lighter components is even less in a barium-flint than in a flint glass having the same percentage of lead. If we, therefore, assume the effect of the elements other than lead and barium to be negligible, equation 7 becomes

$$
C=\frac{\rho_{\mathrm{g} 1}}{\rho_{\mathrm{Pb}}}\left(P_{\mathrm{Pb}}+P_{\mathrm{Ba}} \cdot \frac{(\mu / \rho)_{\mathrm{Ba}}}{(\mu / \rho)_{\mathrm{Pb}}}\right) \text {. }
$$

From this, it is evident that the protection coefficient of a bariumflint glass must depend upon the quality of the incident radiation since the mass absorption coefficients of both lead and barium are involved, both of which are functions of wave length; moreover, the wave-length effect must vary with the percentage of barium $\left(P_{\mathrm{Ba}}\right)$ contained in the glass, as has already been noted in connection with the experimentally determined value. The nature of this dependence is evident from a consideration of the manner in which the mass absorption coefficient of an element varies with effective wave length of a narrow spectral beam. At the critical absorption limits of both lead and barium, there are discontinuities in their respective absorption coefficients, and since these discontinuities occur at different wave lengths, it is evident that there must be distinct discontinuities in the protection coefficient of a glass containing barium. Of particular interest are the discontinuities of these elements at their respective $\mathrm{K}$ absorption limits, which, for lead, occurs at $0.1405 \mathrm{~A}$ and for barium at $0.3307 \mathrm{~A}$. As the X-ray tube voltage is increased, the $\mathrm{K}$ absorption limits of barium are approached from the long wave- 
length side, and at this limit the mass absorption coefficient of barium is increased about sixfold. The composite protection coefficient as given by equation 8 will, therefore, be correspondingly increased. As the tube voltage is increased further, the critical absorption limit of lead is reached at which the absorption coefficient of lead is approximately doubled. For radiation of this quality, the protection coefficient will, therefore, be decreased since the mass absorption coefficient of lead occurs in the denominator of equation 8. As a result of these discontinuities the protection coefficient of a glass containing barium should have a maximum value in the interval $0.1405 \mathrm{~A}\langle\lambda\rangle$ $0.3307 \mathrm{~A}$. In figure 4 the ratio of the mass absorption coefficient of barium to that of lead has been plotted as a function of wave length for a narrow spectral band of radiation.

For heterogeneous radiation, no distinct discontinuities in the protection coefficient, such as shown in figure 4, are to be expected.

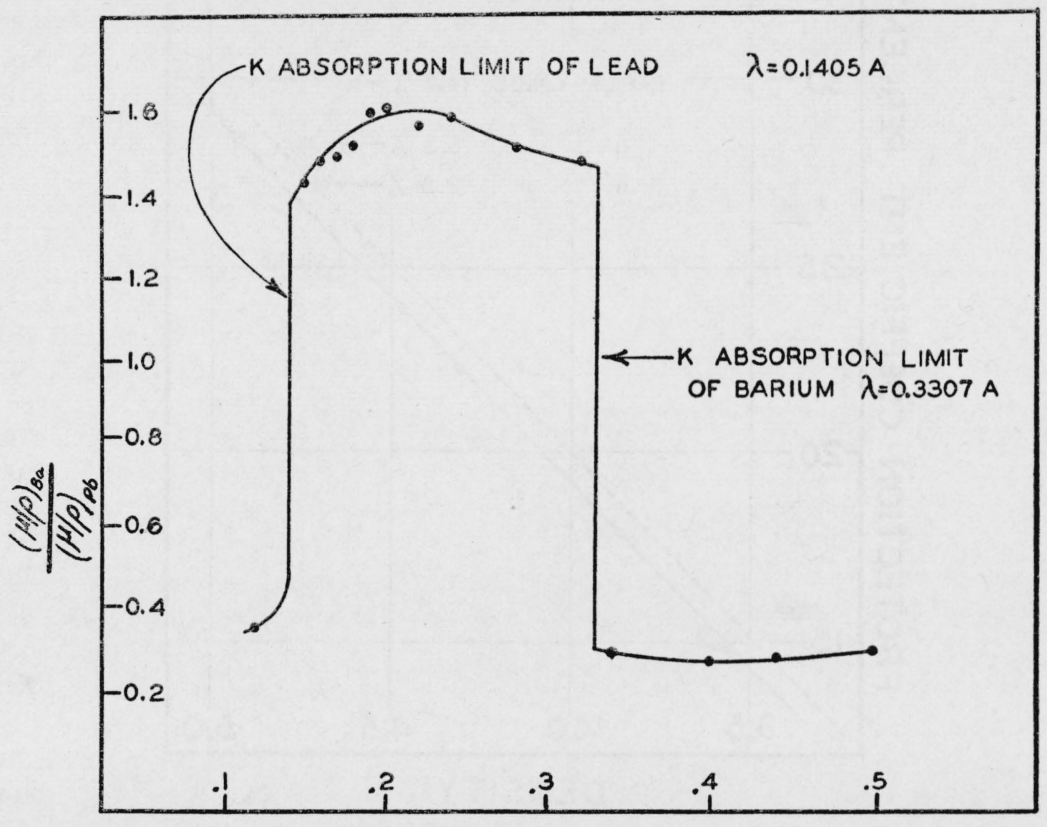

WAVE LENGTH A

FIgURE 4.-The ratio of the mass absorption coefficients of barium and lead as a function of the effective wave length of a narrow spectral band of X-radiation.

However, since any heterogeneous beam having a minimum wave length less than $0.1405 \mathrm{~A}$ has some radiation lying in the abovementioned interval, the effect of the barium component in the glass is to increase the protection coefficient. The actual increase depends upon what fraction of the total energy of the composite beam falls within the interval $0.1405 \mathrm{~A}\langle\lambda\rangle 0.3307 \mathrm{~A}$. As the X-ray-tube voltage is increased above $105 \mathrm{kv}$ less and less of the total energy of the beam falls within this interval and the protection coefficient is correspondingly decreased, as has already been noted from the experimental data. This effect is particularly noticeable in bariumcrown glasses, such as $\mathrm{BC}-1$ and $\mathrm{BC}-3$ of figure 3 . 


\section{EMPIRICAL RELATIONS FOR PROTECTION COEFFICIENT OF FLINT GLASS}

As already noted, the theoretical relations derived for the protection coefficient of glass are limited in their practical usefulness by the simplifying assumptions necessary for their derivation, the most formidable of which is the assumption that the X-radiation is homogeneous. Because of these limitations, empirical relations between the protection coefficient and such properties of the glass as density, refractive index, and lead-oxide and barium-oxide content are desirable. Then, when any one of these properties is known, it may be possible to predict the protection coefficient of a typical X-ray protective glass from these empirical relations without actually

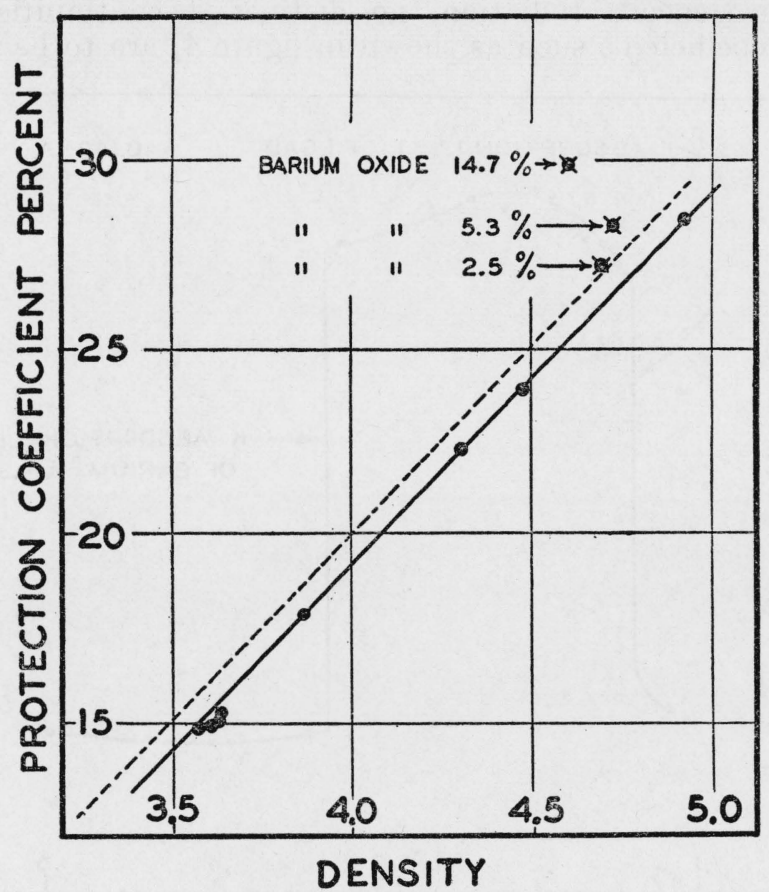

Figure 5.-The protection coefficient of fint glass as a function of the glass density.

determining the protection coefficient experimentally. The values so obtained agree with the accurately determined experimental value to within a few percent and are usually as good as the experimental value obtainable with the apparatus and equipment in the average X-ray laboratory.

It is comparatively easy to find empirical relations for a typical $\mathrm{X}$-ray glass which contains only $\mathrm{PbO}$ as an effective component; for a barium-flint X-ray glass the problem is complicated by the presence of an additional component, $\mathrm{BaO}$.

\section{PROTECTION COEFFICIENT AND DENSITY}

The relation between the protection coefficient and the density of a flint glass is given in figure 5 for typical X-ray glasses ranging in den- 
sity from 3.61 to 4.93 . Over this range, the protection coefficient is found to be a linear function of the glass density, given by the equation:

$$
C=10 \rho_{\mathrm{g} 1}-20.8 ; 3.61<\rho_{\mathrm{g} 1}<4.93,
$$

where again $C$ is the protection coefficient and $\rho_{\mathrm{g} 1}$ the glass density. This is in substantial agreement with a similar equation by Kaye, ${ }^{16}$ derived from a study of flint glasses ranging in density from 3.2 to 4.8 .

Equation 9 , based on data obtained here for $90-\mathrm{kv}$ radiation, holds, within the experimental error, for radiations up to $195 \mathrm{kv}$. The values for $C$ so obtained are about 3 percent lower than Kaye's. The effect of a small barium-oxide component may be noted from the points plotted also in figure 5 for glasses containing small quantities of barium oxide.

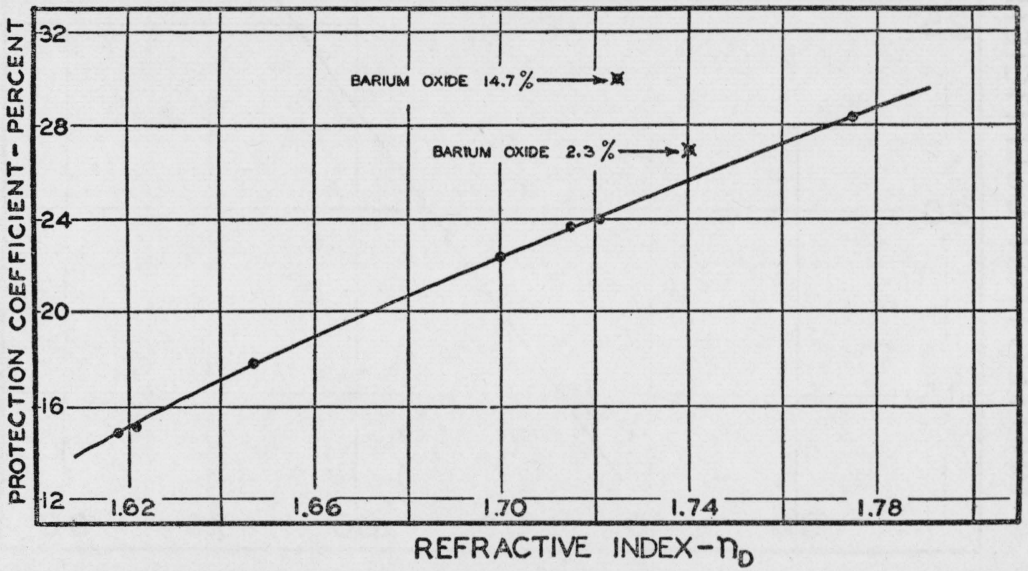

FIGURE 6.-The protection coefficient of flint glass as a function of the refractive index of the glass.

\section{PROTECTION COEFFICIENT AND REFRACTIVE INDEX}

In figure 6 the protection coefficient of each flint glass studied has been plotted against the refractive index of the glass obtained for the $\mathrm{D}$ line of sodium. The effect of a small barium component in increasing the protection coefficient is again apparent. Inasmuch as the refractive index of a glass is readily determined, the curve of figure 6 is a very convenient means for determining the protection coefficient of a flint glass.

\section{PROTECTION COEFFICENT AND CHEMICAL COMPOSITION}

Figure 2 indicates that in general the protection coefficient of a flint glass depends upon the $\mathrm{PbO}$ contained in the glass and increases as this component is increased. Figure 7 shows the more exact nature of this dependence, as made evident by replotting the same data with the protection coefficient as ordinate and the $\mathrm{PbO}$ content of the glass as abscissa. The closed circles represent experimental

\footnotetext{
16 G. W. C. Kaye, Roentgenology, p. 89 (Paul B. Hoeber, Inc., New York, 1929).
} 
data obtained for flint glasses listed in table 2. The open circles are points obtained by means of equation 9 from Wright's ${ }^{17}$ collected data on the relation between the density and the $\mathrm{PbO}$ content of optical flint glasses. The crossed circles are for X-ray glasses containing small amounts of $\mathrm{BaO}$. It appears that the protection coefficient of a flint glass is an increasing function of the percentage of lead oxide. This function is not exactly linear but for a $\mathrm{PbO}$ component

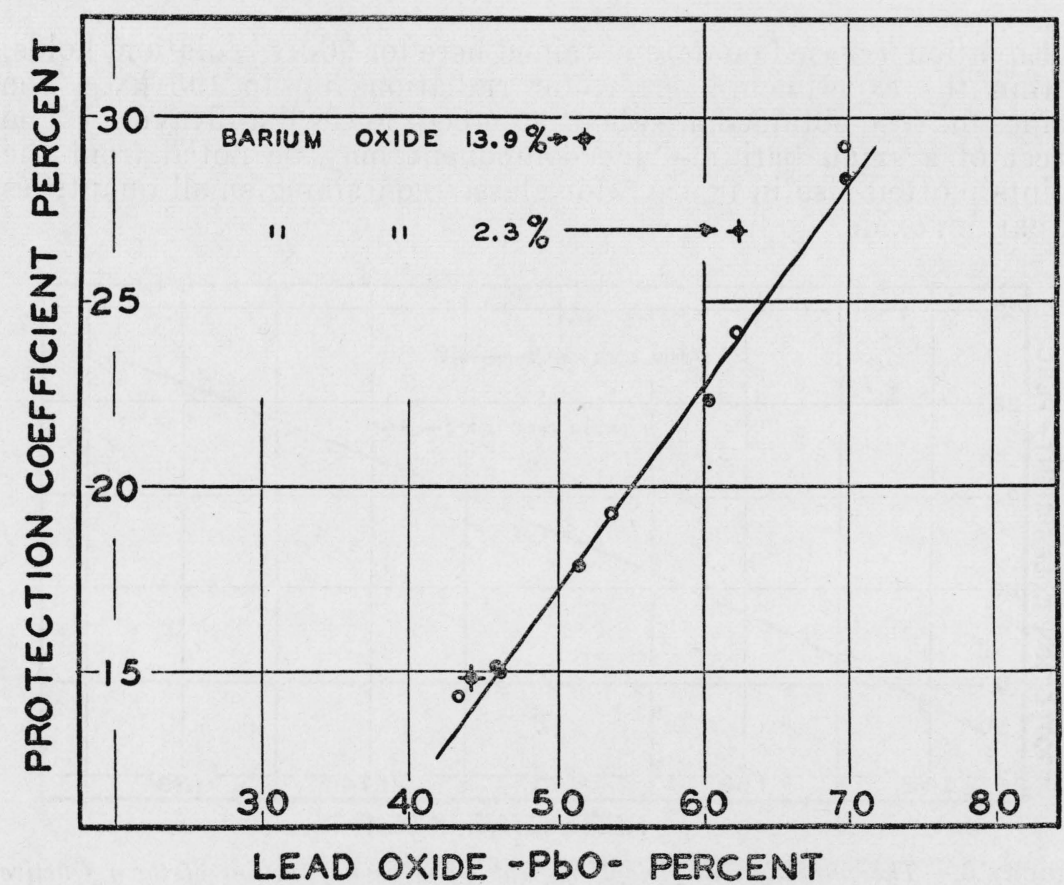

Figure 7.-The protection coefficient of fint glass as a function of the percentage of lead oxide $(\mathrm{PbO})$ contained in the glass.

ranging from 46 to 70 percent, it can be satisfactorily approximated by the straight line equation:

$$
C=0.553\left(P_{\mathrm{PbO}}-19\right) ; 46<P_{\mathrm{PbO}}<70,
$$

where $P_{\mathrm{Pbo}}$ is the percent of $\mathrm{PbO}$ contained in the glass. X-ray glasses commercially available fall well within the range of $\mathrm{PbO}$ components for which this linear approximation is satisfactory.

In table 4 the experimentally determined protection coefficients for $90-$ and $150-\mathrm{kv}$ X-rays of all flint glasses studied are compared with the coefficient calculated by means of equation 10 .

17 The Manufacture of Optical Glass and of Optical Systems, p. 60, Ordnance Dept. Document 2037 (U. S. Government Printing Office, Washington, D. C., 1921). 
TABLE 4.-Flint glasses

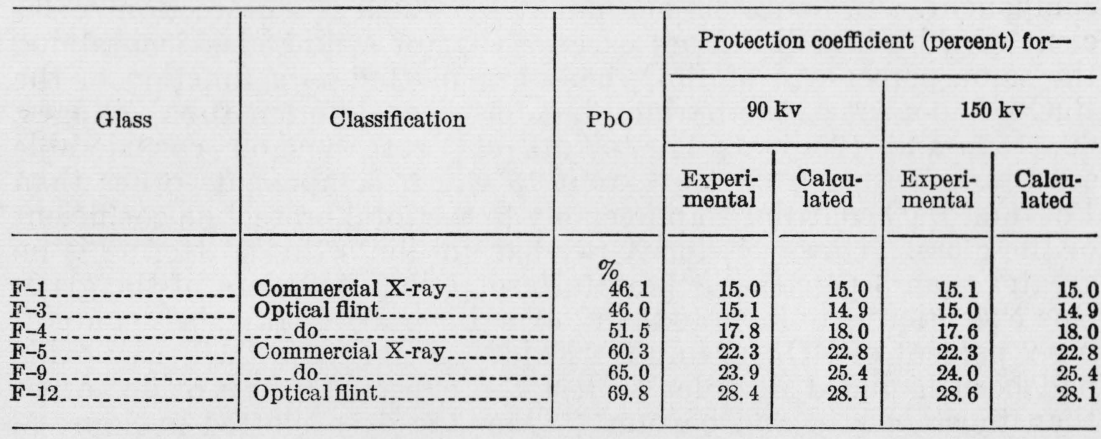

\section{EMPIRICAL RELATIONS FOR BARIUM-FLINT GLASS}

\section{EFFECT OF ADDED BARIUM OXIDE ON PROTECTION COEFFICIENT}

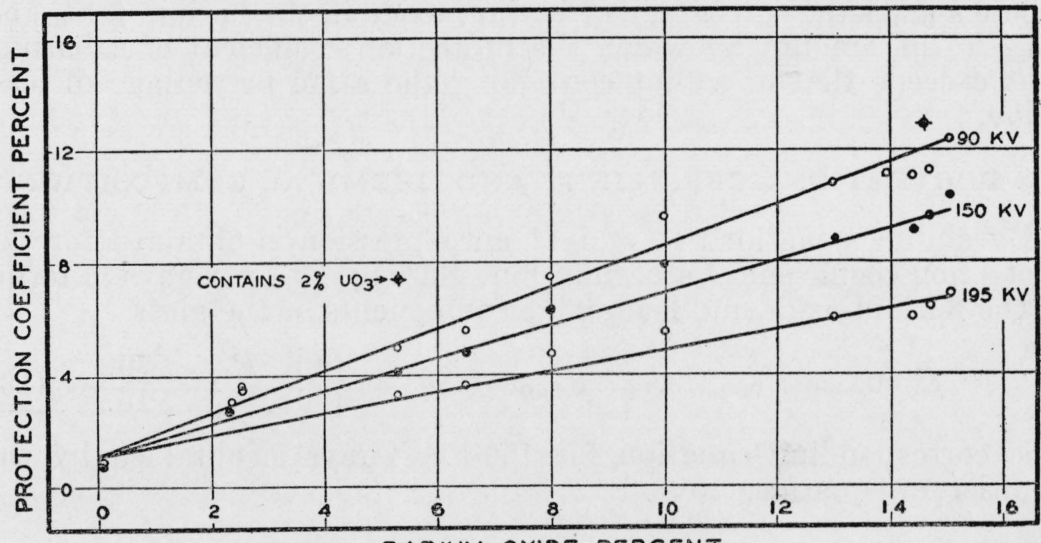

BARIUM OXIDE PERCENT

FIGURE 8.-The component of the total protection coefficient of barium fint glass due to all elements of the glass other than lead plotted as a function of the percentage of barium oxide $(\mathrm{BaO})$ contained in the glass.

That there is a marked increase in the protection coefficient of an $\mathrm{X}$-ray glass when $\mathrm{BaO}$ is added has already been noted in the discussion of figure 3 . Some idea of the effectiveness of even a very small $\mathrm{BaO}$ component in an X-ray glass can be obtained from figure 7 in which, for $90-\mathrm{kv}$ radiation, the two points with crosses are for glasses containing 2.3 and 13.9 percent of $\mathrm{BaO}$ in addition to their $\mathrm{PbO}$ component. It is apparent that for radiation of this quality, as little as 0.5 percent of $\mathrm{BaO}$ results in an appreciable increase in the protection coefficient of the glass. For more penetrating radiation the effect of the $\mathrm{BaO}$ component is less, but is still appreciable.

Further study of the relation between this increase in protection coefficient with the $\mathrm{BaO}$ component of the glass reveals that for radiation of a given quality, the amount by which the coefficient is increased is approximately a linear function of the $\mathrm{BaO}$ component 
and, as is to be expected, is essentially independent of the $\mathrm{PbO}$ component. In figure 8 the amount by which the protection coefficient of a barium-flint glass exceeds that of a flint glass containing the same percentage of $\mathrm{PbO}$, has been plotted as a function of the $\mathrm{BaO}$ component of the barium-flint for three different tube voltages, 90,150 , and $195 \mathrm{kv}$. The points of figure 8 show considerable scattering arising from the extent to which components other than $\mathrm{PbO}$ and $\mathrm{BaO}$ contribute appreciably to the total protection coefficient of the glass. However, for X-ray barium flints this scattering is no greater than 3 percent of the total protection coefficient of the glass. One exception is to be noted, an "experimental" X-ray glass containing 2 percent of $\mathrm{UO}_{3}$ (uranium trioxide); in this case the heavy oxide had been included in order to test the effect of heavy oxides other than those of lead and barium. From the data plotted in figure 8, the following relations have been obtained:

$\left.\begin{array}{l}\text { For } 90 \mathrm{kv}: C_{\mathrm{BaO}}=0.727 P_{\mathrm{BaO}}+1.2 \\ \text { For } 150 \mathrm{kv}: C_{\mathrm{BaO}}=0.586 P_{\mathrm{BaO}}+1.0\end{array}\right\} 0<P_{\mathrm{BaO}}<15$,

where $P_{\mathrm{BaO}}$ is the percentage of barium oxide in the barium flint, and $C_{\mathrm{BaO}}$ is the amount by which the protection coefficient of a barium flint exceeds that of a flint containing the same percentage of lead oxide.

\section{PROTECTION COEFFICIENT AND CHEMICAL COMPOSITION}

By adding equations 10 and 11 an expression is obtained for the protection coefficient of a barium-flint glass for $90-\mathrm{kv}$ X-rays in terms of the barium-oxide and lead-oxide components of the glass.

$$
C=0.553 P_{\mathrm{Pbo}}+0.727 P_{\mathrm{BaO}}-9.3 \quad\left\{\begin{aligned}
46 & <P_{\mathrm{PbO}}<70 . \\
0 & <P_{\mathrm{BaO}}<15 .
\end{aligned}\right.
$$

The corresponding equation for $150-\mathrm{kv}$ X-rays is obtained by the addition of equations 10 and 12 ;

$$
C=0.553 P_{\mathrm{PbO}}+0.586 P_{\mathrm{BaO}}-9.5 \quad\left\{\begin{aligned}
46 & <P_{\mathrm{PbO}}<70 . \\
0 & <P_{\mathrm{BaO}}<15 .
\end{aligned}\right.
$$

Equations 13 and 14 are based on observations of flint glasses approximately $6 \mathrm{~mm}$ thick. Kaye ${ }^{18}$ has reported that for radiation of a given quality the lead equivalent of barium-sulphate plaster is not strictly proportional to the thickness of the material. He found that the departure from the linear relationship between lead equivalent and thickness increases with the X-ray voltage and is quite marked for 200-kv X-rays. Equations 13 and 14 have been tested for glasses up to $10.0 \mathrm{~mm}$ in thickness and have been found satisfactory. However, it should not be assumed that these equations are valid for glasses varying very much from the thickness for which they were derived.

In table 5, the experimentally determined protection coefficients for 90 and 150-kv X-rays of all barium-flint glasses studied are compared with the coefficients calculated by means of the empirical equations 13 and 14.

\footnotetext{
${ }_{18}$ G. W. C. Kaye, Roentgenology, p. 93 (Paul B. Hoeber, Inc., New York, 1929).
} 
TABLE 5.-Experimental value of protection coefficient of barium fint glasses compared with values calculated by means of equations 14 and 15

\begin{tabular}{|c|c|c|c|c|c|c|}
\hline \multirow{3}{*}{ Glass } & \multirow{3}{*}{$\mathrm{PbO}$} & \multirow{3}{*}{$\mathrm{BaO}$} & \multicolumn{4}{|c|}{ Protection coefficient (percent) for- } \\
\hline & & & \multicolumn{2}{|c|}{$90 \mathrm{kv}$} & \multicolumn{2}{|c|}{$150 \mathrm{kv}$} \\
\hline & & & $\begin{array}{l}\text { Experi- } \\
\text { mental }\end{array}$ & Calculated & $\begin{array}{l}\text { Experi- } \\
\text { mental }\end{array}$ & Calculated \\
\hline $\begin{array}{l}\mathrm{BF}-1 \mathrm{a} \\
\mathrm{BF}-2 \mathrm{a}-\ldots \\
\mathrm{BF}-3 \mathrm{a}-\ldots \\
\mathrm{BF}-5 \\
\mathrm{BF}-7\end{array}$ & $\begin{array}{c}\%^{6} .87 \\
23.5 \\
44.1 \\
47.1 \\
45.38\end{array}$ & $\begin{array}{c}\% \\
29.15 \\
14.5 \\
<.1 \\
14.35 \\
15.02\end{array}$ & $\begin{array}{l}15.3 \\
14.8 \\
26.4 \\
26.6\end{array}$ & $\begin{array}{l}15.7 \\
14.2 \\
15.1 \\
27.2 \\
26.7\end{array}$ & $\begin{array}{l}13.6 \\
14.7 \\
24.6 \\
24.7\end{array}$ & $\begin{array}{l}11.4 \\
12.0 \\
14.9 \\
25.0 \\
24.4\end{array}$ \\
\hline $\begin{array}{l}\text { BF-9 } \\
\text { BF-12-14 } \\
\text { BF-15 } \\
\text { BF-17 }\end{array}$ & $\begin{array}{l}60.0 \\
52.0 \\
53.15 \\
52.6 \\
51.2\end{array}$ & $\begin{array}{l}<.1 \\
\text { 13. } 94 \\
13.01 \\
14.7 \\
15.50\end{array}$ & $\begin{array}{l}23.4 \\
29.4 \\
30.0 \\
29.9 \\
29.7\end{array}$ & $\begin{array}{l}24.0 \\
29.6 \\
29.6 \\
30.5 \\
30.3\end{array}$ & $\begin{array}{l}23.5 \\
27.7 \\
27.7 \\
28.2 \\
28.0\end{array}$ & $\begin{array}{l}23.7 \\
27.4 \\
27.5 \\
28.2 \\
27.9\end{array}$ \\
\hline $\begin{array}{l}\text { BF-18 } \\
\text { BF-20- } \\
\text { BF-22 } \\
\text { BF-24 } \\
\text { BF-26. }\end{array}$ & $\begin{array}{l}62.6 \\
61.6 \\
60.9 \\
62.1 \\
61.24\end{array}$ & $\begin{array}{l}2.34 \\
2.52 \\
6.5 \\
5.3 \\
5.50\end{array}$ & $\begin{array}{l}27.0 \\
27.0 \\
28.3 \\
28.4 \\
28.7\end{array}$ & $\begin{array}{l}27.0 \\
26.6 \\
29.1 \\
28.9 \\
28.0\end{array}$ & $\begin{array}{l}26.5 \\
27.0 \\
28.0 \\
28.0 \\
28.1\end{array}$ & $\begin{array}{l}26.5 \\
26.0 \\
28.0 \\
28.0 \\
27.6\end{array}$ \\
\hline $\begin{array}{l}\text { BF-27 b- } \\
\text { BF-28 } \\
\text { BF-29. } \\
\text { BF-30 } \\
\text { BF-31 }\end{array}$ & $\begin{array}{l}52.6 \\
62.0 \\
62.0 \\
62.0 \\
61.0\end{array}$ & $\begin{array}{r}14.6 \\
5.3 \\
8.0 \\
10.0 \\
9.7\end{array}$ & $\begin{array}{l}31.0 \\
30.5 \\
31.4 \\
33.4\end{array}$ & $\begin{array}{r}30.4 \\
28.8 \\
30.2 \\
32.3 \\
\end{array}$ & $\begin{array}{l}28.8 \\
29.6 \\
30.1 \\
31.7 \\
30.6\end{array}$ & $\begin{array}{l}28.1 \\
27.9 \\
29.5 \\
30.7 \\
29.9\end{array}$ \\
\hline
\end{tabular}

s Equations 13 and 14 do not strictly apply here since the percentage of lead oxide $(\mathrm{PbO})$ in these glasses is less than 46 percent.

Glass BF-27 is an experimental X-ray glass containing 5 percent of $\mathrm{TiO}_{2}$.

- Glass BF-28 is an experimental X-ray glass containing 2 percent of $\mathrm{UO}_{3}$.

The writer acknowledges the cooperation, assistance, and advice of Lauriston S. Taylor, under whose supervision this work was done.

Washington, February 6, 1936. 